\title{
La gestión del utillaje óseo de la Edad del Bronce en el yacimiento de El Portalón de Cueva Mayor, Sierra de Atapuerca, Burgos
}

\author{
The Management of Bone Tools from the Bronze Age Site of \\ El Portalón of Cueva Mayor, Sierra de Atapuerca, Burgos
}

\author{
Amalia Pérez Romero \\ Laboratorio de Evolución Humana. Universidad de Burgos \\ apromero@ubu.es \\ José Miguel Carretero Díaz \\ Laboratorio de Evolución Humana. Universidad de Burgos \\ jmcarre@ubu.es
}

\author{
Alfonso Alday Ruiz \\ Área de Prehistoria. Universidad del País Vasco \\ a.alday@ehu.es
}

María Ángeles Galindo Pellicena

Centro Mixto Universidad Complutense-Instituto de Salud Carlos III de Evolución y Comportamiento Humanos,
Madrid
mgalindo@isciii.es
Gema AdÁn ÁLVAREZ
Centro Asociado U.N.E.D. Asturias
geadan@gijon.uned.es
Laura JUEZ APARICIO
Laboratorio de Evolución Humana. Universidad de Burgos
ljuez76@gmail.com

Juan Luis Arsuaga Ferreras

Centro Mixto Universidad Complutense-Instituto de Salud Carlos III de Evolución y Comportamiento Humanos. Departamento de Paleontología, Universidad Complutense de Madrid, Madrid jlarsuaga@isciii.es

\begin{abstract}
RESUMEN
Se analiza el utillaje óseo de la Edad del Bronce recuperado en el yacimiento arqueológico de El Portalón de Cueva Mayor, en la sierra de Atapuerca (Burgos). A dia de hoy la Edad del Bronce es el periodo cultural mejor representado en la cavidad y su estudio nos ha obligado a unificar los distintos criterios de excavación y definición estratigráfica seguidos desde las primeras actuaciones arqueológicas de J.M. Apellániz hasta las del actual equipo de investigación de Atapuerca (EIA). Se han correlacionado, por primera vez, el inicial sistema de "lechos" de Apellániz y la reciente lectura sedimentaria que reconoce 11 niveles cuyas dataciones radiométricas se encadenan desde fines del Pleistoceno a la Edad Media. El conjunto óseo recuperado de la Edad del Bronce incluye útiles y elementos de adorno muy variados con características tanto autóctonas como alóctonas, que indican la existencia de relaciones a corta y larga distancia en el seno de las poblaciones prehistóricas del interior peninsular.
\end{abstract}


Palabras Clave: Sierra de Atapuerca, Portalón de Cueva Mayor, holoceno, Edad del Bronce, industria ósea.

\begin{abstract}
In this paper we analyze the set of Bronze Age bone tools recovered at the archaeological site of El Portalón of Cueva Mayor in the Sierra de Atapuerca (Burgos). The Bronze Age cultural period is the best represented in the cavity and its study has forced us to unify the different excavation and stratigraphical criteria undertaken from the earliest archaeological excavations developed by J.M. Apellaniz during the 70s until the excavations of the current research team (EIA) since 2000. We propose here for the first time a relationship between the initial system of "beds" used by Apellániz and our recent sedimentary sequence that recognizes eleven stratigraphic levels radiometrically dated from the late Upper Pleistocene to the Middle Age. Within the bone industry assemblage we recognize a large variety of utensils and ornamental elements, with native and allochthonous features, that make evident a regional as well as long distance relationships of these populations of the interior of the Iberian Peninsula during the recent Prehistory.
\end{abstract}

Key words: Sierra de Atapuerca, Portalón de Cueva Mayor, Holocene, Bronze Age, Bone Industry.

\section{Introducción}

El desarrollo de una industria sobre soportes duros animales es una de las características del Paleolítico superior. Luego, tras varios milenios, donde el instrumental escasea y se reduce a tipos muy primarios, desde el Neolítico avanzado y durante las Edades de los Metales, conoce una nueva fase de esplendor. En este contexto el yacimiento de El Portalón de Cueva Mayor viene entregando un inventario numeroso y diversificado de herramientas sobre hueso. Aquí presentamos el correspondiente a la Edad del Bronce ofreciendo su lectura tipológica, estudiando los soportes, proponiendo, en los casos que ha sido posible, una aproximación tecnológica, constatando su evolución llamando a sus paralelos y, en definitiva, intentando comprender su significado.

\section{El yacimiento de El Portalón de Cueva Mayor}

\subsection{Localización geográfica}

La Sierra de Atapuerca, situada a unos $15 \mathrm{Km}$ al Este de la ciudad de Burgos, forma parte de las estribaciones del Sistema Ibérico en el sector conocido como "Corredor de la Bureba", punto de contacto entre este sistema, la Cordillera Cantábrica y la Meseta (Fig. 1). La sierra, bien conocida por sus yacimientos Pleistocenos, presenta, también, un rico y variado registro de la Prehistoria reciente, destacando las cavidades del Sistema kárstico de Cueva Mayor, en cuya entrada, conocida como El Portalón, se registra una prolongada ocupación humana desde el Mesolítico hasta épocas históricas (Apellániz y Domingo 1987; Clark 1979; Mínguez 2005; Carretero et al. 2008, Pérez-Romero 2009). Es interesante retener las dimensiones del yacimiento para comprender mejor las capacidades de acogida y sus posibilidades: la sala de entrada supera los 200 metros cuadrados, y da acceso a galerías interiores que sabemos fueron exploradas en la antigüedad e, incluso, sirvieron para el desarrollo de actividades artísticas. Las excavaciones arqueológicas demuestran la intensidad de las actividades desarrolladas y para la Edad del Bronce, época que ahora interesa, se atestigua el valor de la cavidad para la gestión de fauna doméstica, con algún tipo de estabulación, e incluso, complejas estructura con rellenos de espacios con tierras aportadas de fuera para acondicionar el espacio y hacerlo más habitable. Es importante transmitir esta actividad desarrollada por los habitantes de El Portalón en las Edades de los Metales, porque ayudan a entender el significado de la industria ósea que describiremos. Se inserta en un conjunto de estrategias dinámicas desarrolladas por el grupo, y en algunos casos demuestran, aquí también, el interés por la ostentación.

\subsection{Contexto arqueológico}

El yacimiento de El Portalón es conocido desde el S. XIX gracias a los trabajos de Sampayo y Zuaznávar (1868), Breuil y Obermaier (1913) y las decisivas intervenciones de Francisco Jordá (inéditas), Geoffrey Clark (Clark 1979) y Juan $\mathrm{M}^{\mathrm{a}}$ Apellániz (Apellániz et al. 1983; Mínguez 2005). Este último investigador desarrolló, entre 1973 y 1983, dos áreas de trabajo que se fueron excavando "por lechos" definidos como "la unidad de depósito de materiales en un lapso de tiempo que se establece tomando como referencia los criterios de depósito de los materiales: huesos grandes 


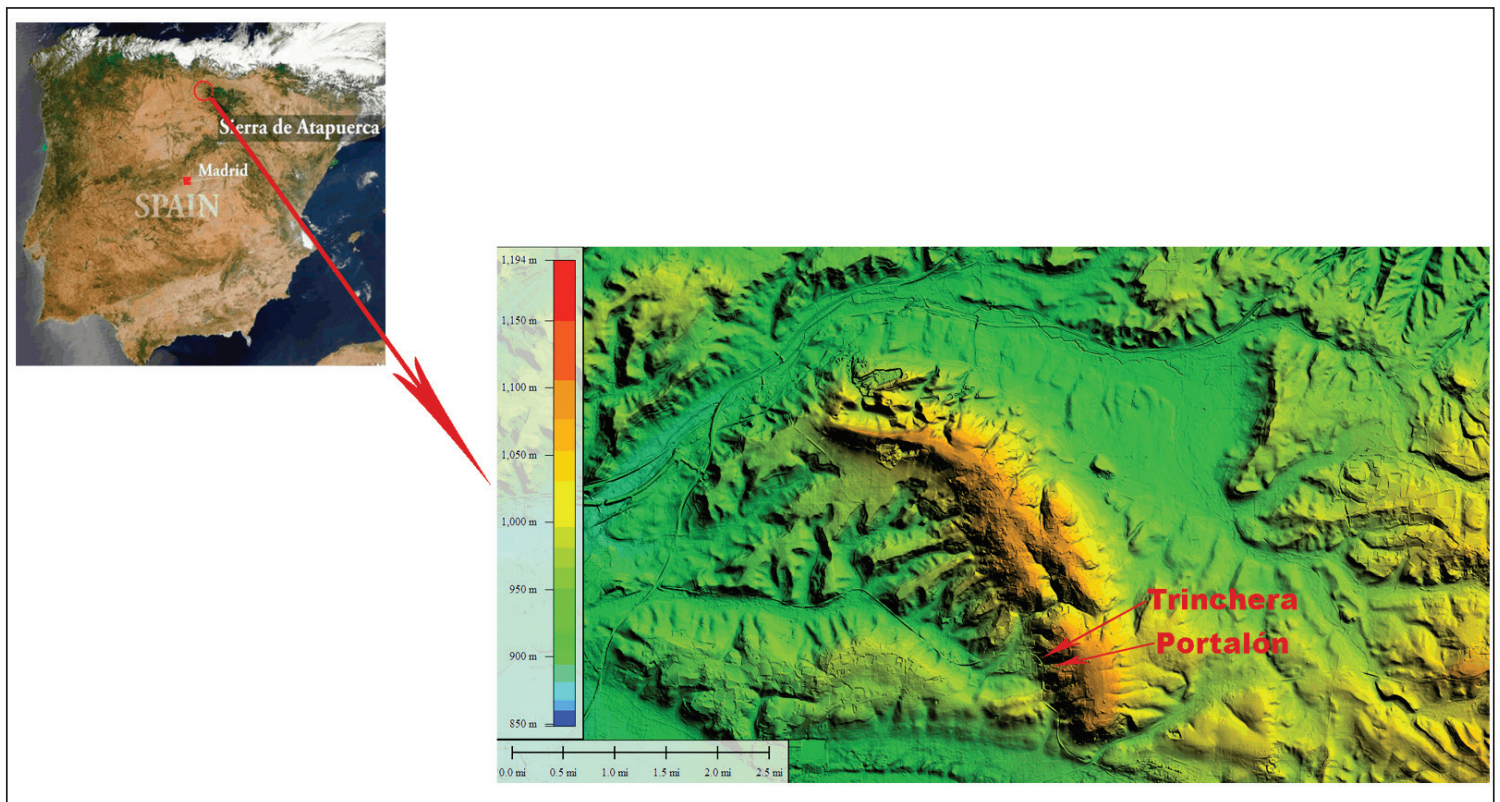

Fig. 1. Localización de la sierra de Atapuerca donde se encuentra el yacimiento de El Portalón de Cueva Mayor.

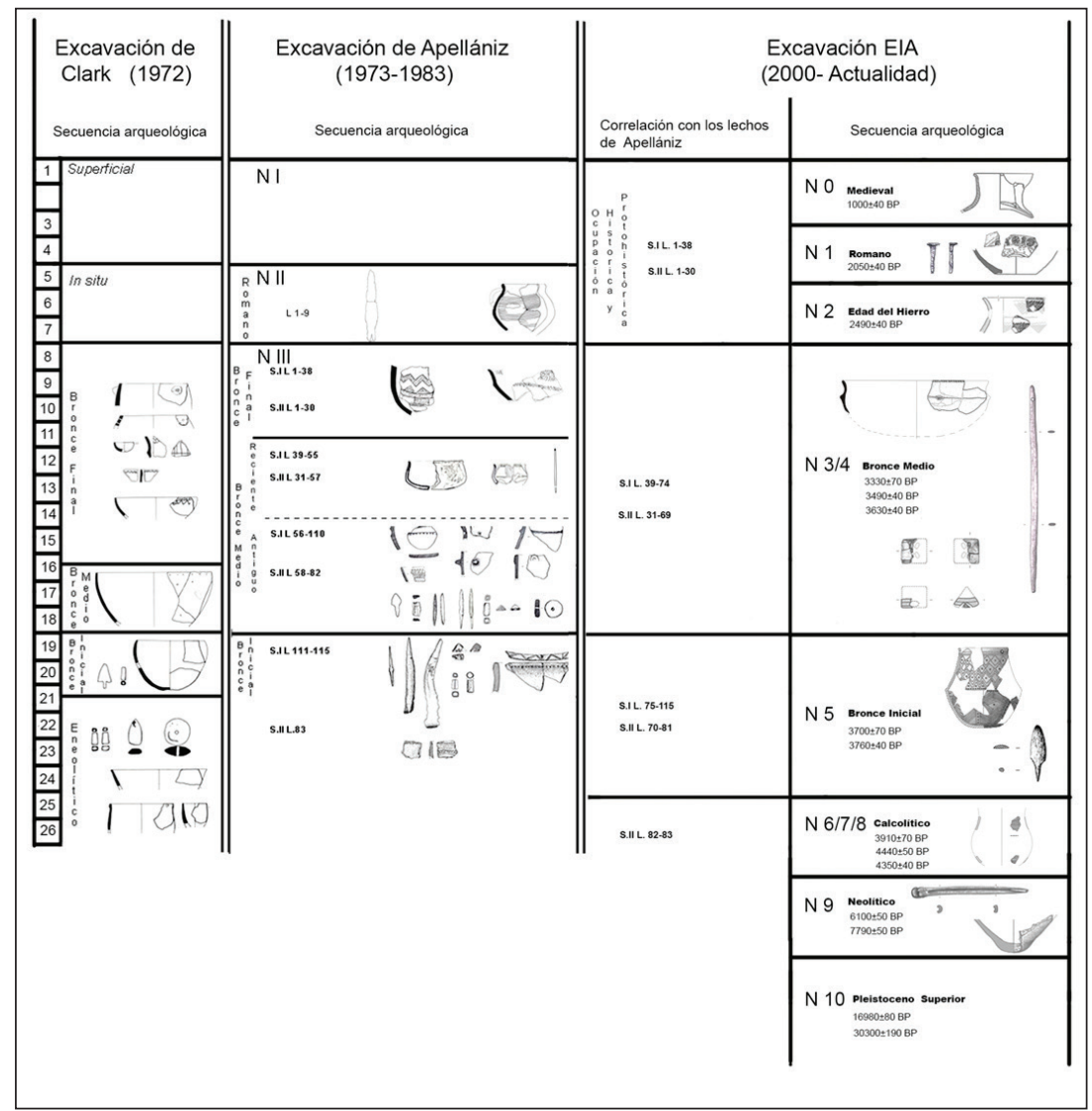

Fig. 2. Propuesta de correlación estratigráfica y cultural entre los niveles excavados por J. M. Apellániz y los llevados a cabo por el Equipo actual de Investigación de Atapuerca (EIA). 


\section{CORRESPONDENCL ESTRATIGRÁFICA DE LAS PRINCIPALES INTERVENCIONES ARQUEOLÓGICAS EN EL PORTALÓN}

\begin{tabular}{|c|c|c|c|c|c|c|c|c|c|c|c|}
\hline \multirow{4}{*}{$\begin{array}{l}\text { Periodes } \\
\text { Culturales }\end{array}$} & \multicolumn{11}{|c|}{ Intervenciones Arqueologicas } \\
\hline & $\begin{array}{l}\text { CLARK } \\
\text { (19N0) }\end{array}$ & \multicolumn{6}{|c|}{ APELLAXNZ (1973-1985) } & \multicolumn{4}{|c|}{ E.LA (2000 - actualidad) } \\
\hline & \multirow[b]{2}{*}{ Nivel } & \multirow[b]{2}{*}{ Nivel } & \multirow[t]{2}{*}{ Lecho } & Sector & \multicolumn{3}{|c|}{ Datacioeses } & \multirow[b]{2}{*}{ Nivel } & \multicolumn{3}{|c|}{ Dataciones } \\
\hline & & & & & $\begin{array}{c}\text { Coevencional } \\
\text { BP }\end{array}$ & Cal.BBC & Lab. & & $\begin{array}{l}\text { Comencional } \\
\text { BP }\end{array}$ & Callec & Lab. \\
\hline \multirow{5}{*}{$\begin{array}{l}\text { Épeca } \\
\text { Histórica }\end{array}$} & \multirow{5}{*}{1.7} & & & S. I & & & & \multirow{5}{*}{$0 / 1$} & & & \\
\hline & & I & $\begin{array}{l}A, B \\
C, D\end{array}$ & S. II & & & & & $1000 \pm 40$ & $\begin{array}{l}980 . \\
1150\end{array}$ & $\begin{array}{l}\text { Beta- } \\
224081\end{array}$ \\
\hline & & Suparficial & yF & & & & & & & & \\
\hline & & \multirow[b]{2}{*}{ II } & \multirow[b]{2}{*}{$1-9$} & S. I & & & & & & & \\
\hline & & & & S. II & & & & & $1980 \div 40$ & $\begin{array}{l}50 \mathrm{BC}- \\
10 \mathrm{AC}\end{array}$ & $\begin{array}{l}\text { Beta- } \\
212136\end{array}$ \\
\hline \multirow[t]{2}{*}{ Pretohisteria } & & & & & & & & \multirow[t]{2}{*}{2} & & & Beta- \\
\hline & & & & & & & & & $2490 \pm 40$ & 790.420 & 222385 \\
\hline \multirow{2}{*}{$\begin{array}{l}\text { Bronce } \\
\text { Pinal }\end{array}$} & \multirow[b]{2}{*}{8.16} & & $1-38$ & S I & & & & & & & \\
\hline & & & 1.30 & S II & & & & & & & \\
\hline \multirow{7}{*}{$\begin{array}{l}\text { Bronce } \\
\text { Medis }\end{array}$} & \multirow{7}{*}{$17-18$} & & & & $3470 \pm 190$ & $\begin{array}{l}2341- \\
1379\end{array}$ & $1-9880$ & & $3330 \div 70$ & $\begin{array}{l}1760- \\
1640\end{array}$ & $\begin{array}{l}\text { Beta- } \\
153260\end{array}$ \\
\hline & & & $39-74$ & SI & $3340 \pm 160$ & 2039 & $1-9881$ & & & $2030-$ & Beta- \\
\hline & & & & & & 1260 & & 314 & $3560 \leq 50$ & 1750 & 222336 \\
\hline & & & & & $3400 \pm 50$ & 1783 & CSIC- & & & $1750-$ & Beta- \\
\hline & & & & & & 1605 & 532 & & $3330=60$ & 1490 & 201761 \\
\hline & & & $31-69$ & & $3430 \pm 50$ & 1883 & ब्ञाट & & & $1910-$ & Beta : \\
\hline & & & & S II & & 1622 & & & $3560+40$ & 1700 & 212188 \\
\hline & & & 75. & & & & & & & 21030. & Beta- \\
\hline & & & 115 & S I & & & & & $3630 \pm 40$ & 1890 & 153362 \\
\hline Hronee & 19.20 & & & & & & & 5 & & 2140 & Beta- \\
\hline Antigus & & & $70-81$ & & & & & & $3650 \pm 40$ & 1910 & 209453 \\
\hline & & & & S II & & & & & & $2310-$ & Beta- \\
\hline & & III & & & & & & & $3760+40$ & 2030 & 204454 \\
\hline & & & & & & & & & & $2230-$ & Beta- \\
\hline & & & & & & & & & $3740 \pm 40$ & 2060 & 212189 \\
\hline & & & & & & & & & & 2580 . & Beta- \\
\hline Calceliticel & $21-26$ & & $82-83$ & SIII & & & & $6 / 7 / 8$ & $3910+70$ & 22000 & 153363 \\
\hline & & & & & & & & & & 3340. & Beta- \\
\hline & & & & & & & & & $4440 \pm 50$ & 2920 & 197389 \\
\hline & & & & & & & & & & $3080-$ & Beta- \\
\hline & & & & & & & & & $4350=50$ & 2900 & 337300 \\
\hline & & & & & & & & & & $3930-$ & Beta- \\
\hline & & & & & & & & & $4990=50$ & 3670 & 184841 \\
\hline Neolitice & & & & & & & & 9 & & $5210-$ & Beta: \\
\hline & & & & & & & & & $6100 \pm 50$ & $4860-$ & 222339 \\
\hline & & & & & & & & & & 6680. & Beta- \\
\hline & & & & & & & & & $7790 \pm 40$ & 6500 & 197387 \\
\hline & & & & & & & & & & $18770-$ & Beta- \\
\hline Plewstoseno & & & & & & & & 10 & $16980 \pm 80$ & 17780 & 209452 \\
\hline Seaperior & & & & & & & & & & & Beta- \\
\hline & & & & & & & & & $30300+190$ & & 212190 \\
\hline
\end{tabular}

Tabla. 1. Correspondencia entre los diferentes niveles definidos en las 3 principales intervenciones arqueológicas llevadas a cabo en El Portalón, anotando los valores radiométricos de cada unidad. 
y largos, lajas de piedra, fragmentos grandes y manchas de ceniza" (Mínguez 2001: 46; 2005: 49).

Con el fin de conocer mejor el potencial arqueológico de El Portalón, está en marcha, desde el año 2000, una nueva etapa de excavaciones dentro del proyecto de Investigación de Atapuerca que ha revelado una secuencia estratigráfica de más de $10 \mathrm{~m}$ de potencia con una unidad sedimentaria del Holoceno, dividida en diez niveles, y otra unidad infrayacente del Pleistoceno superior con escasas huellas de presencia humana. En total 11 niveles sedimentarios. El registro material y una larga serie radiocronológica evidencian ocupaciones de la Edad Media, Epoca Romana, Edad del Hierro I, toda la Edad del Bronce, Calcolítico, Neolítico, Mesolítico y del Pleistoceno superior (Tab. 1) (Carretero et al. 2008).

Entre los objetivos actuales está la correlación y unificación de las diferentes lecturas sedimentológicas (propuesta en cada intervención desde diferentes criterios), con el fin de obtener una interpretación de las distintas ocupaciones del yacimiento y del valor de sus industrias (Tab. 1).

En este sentido recordemos que Apellániz, estableció una secuencia con tres niveles adscribiendo y dividiendo el inferior (III), en Bronce antiguo, medio y final (Apellániz y Domingo 1987). Consultando sus memorias y diarios de campo, las nuevas dataciones de $\mathrm{C}^{14}$ así como el estudio tipológico de las cerámicas, proponemos una nueva lectura cronocultural (Fig. 2) que diferencia ocupaciones del Bronce inicial y medio, hasta el momento, pero no de su tramo final $(\mathrm{Ca}-$ rretero et al. 2008).

A partir de este momento, para el Portalón ya no nos referiremos a los lechos definidos por Apellániz, sino a los niveles estratigráficos tal y como se han definido en la actualidad (Carretero et al. 2008).

\section{Metodología}

\subsection{Elementos de análisis}

Las excavaciones realizadas en El Portalón están aportando ricos y variados elementos de cultura material (cerámica, lítica, metálica...), ocupándonos en el presente trabajo de la industria ósea de la Edad del Bronce. Estamos ahora en disposición de realizar una lectura conjunta de su inventario, aunando lo recuperado por nosotros y, una parte de lo correspondiente a los trabajos de
Clark y de Apellániz, con el objetivo de acercarnos al sentido que pudieron tener estos objetos. Teniendo en cuenta los contextos describiremos la materia prima utilizada, la morfología de las piezas, las huellas de fabricación y uso y buscaremos los paralelos reconocidos en otros yacimientos aproximadamente contemporáneos.

\subsubsection{La colección de materiales}

El número de piezas de industria ósea relacionadas con los niveles correspondientes a la Edad del Bronce es de 70, 50 correspondientes al Bronce antiguo y 20 al Bronce medio. Se trata de útiles completos o casi completos, en materia dura de origen animal (hueso, asta o piezas dentales) a la que añadiremos la malacofauna. No se incluyen en este trabajo los huesos con marcas de carnicería ni aquellos que presenten superficies alteradas por procesos postdeposicionales (mordisqueos, procesos físicos y químicos, etc.).

El inventario presenta, por lo general, un estado de conservación bastante bueno y son escasos los elementos fracturados, facilitando su clasificación y detectando en algunos casos, los procesos técnicos de fabricación y las diversas trazas antrópicas.

\subsubsection{La materia prima y los soportes}

Se han identificado taxonómicamente 2.380 restos de fauna en los niveles del Bronce. Tanto en el Bronce antiguo como en el medio se han podido determinar la presencia de ovicaprinos $(32,37 \%$ en el Bronce antiguo y $32,46 \%$ en el Bronce medio), Bos taurus (B. antiguo 27,28\%; B. medio 35,74\%); Sus domesticus (B. antiguo 10,09\%; B. medio 7,54\%); Equus sp.gr. Equus ferus/Equus caballus (B. antiguo 20,65\%; B. medio 14,21\%); Canis familiaris (B. antiguo 3,17\%; B. medio 6,99\%); Cervus elaphus (B. antiguo 1,06\%; B. medio 2,19\%); Capreolus capreolus (B. antiguo $0,19 \%$; B. medio $0,22 \%$ ) y lepóridos (B. antiguo $4.51 \%$; B. medio 0,55\%). Sus scrofa y Vulpes vulpes están representados en el Bronce inicial con $0,3 \%$ y 0,4 respectivamente para ausentarse en el Bronce medio.

Como soporte de las herramientas se eligieron distintas pates del endoesqueleto $(41 ; 71 \%)$ junto a astas $(10 ; 17 \%)$, piezas dentarias $(2 ; 3 \%) \mathrm{y}$, como bases aloctonas, conchas $(4 ; 7 \%)$ y marfil (1; 2\%) (Fig. 3). Aunque no forma parte de este estudio, hay un ejemplo de industria ósea sobre hueso humano. 


\section{Bases Materiales}

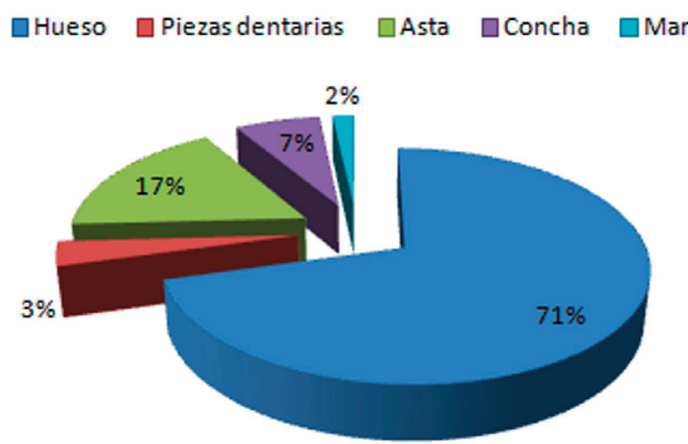

Fig. 3. Contribución en tantos por ciento de cada una de las bases materiales.

La determinación del origen taxonómico del soporte ha resultado muy compleja dadas las alteraciones sufridas durante el proceso de fabricación o por su uso posterior. De los 30 elementos en los que ha sido posible esta determinación (34\%), hay un leve predominio de las especies domésticas frente a las salvajes.

\subsubsection{Tipologías analíticas}

Para la definición, clasificación y estudio morfofuncional hemos tomado como referentes las listas-tipo generales y especificas (Barandiarán 1964; Alday 1987; Rodanes 1987; Camps-Fabrer 1990; Uscatescu 1992; Averbouh 1995; Pascual Benito 1998; Maicas 2003-2004 y 2007 Altamirano 2011; López Padilla 2011, Adán 2013) pero centrándonos especialmente en las de Maicas Ramos, Altamirano y Pascual Benito.

La primera división de los 70 elementos en dos grandes grupos morfofuncionales distingue entre útiles 44 (62\%) (33 del Bronce antiguo y 11 del Bronce medio) y elementos de adorno 26 (38\%) (17 del Bronce antiguo y 9 del Bronce medio) (fig.4).

\section{Descripción de los objetos}

Organizamos la exposición del inventario distribuyendo los efectivos según los grupos tipológicos representados (apuntado, romos y objetos de adorno), señalando en la Tabla 2 lo correspondiente a cada uno de los niveles estratigráficoculturales.
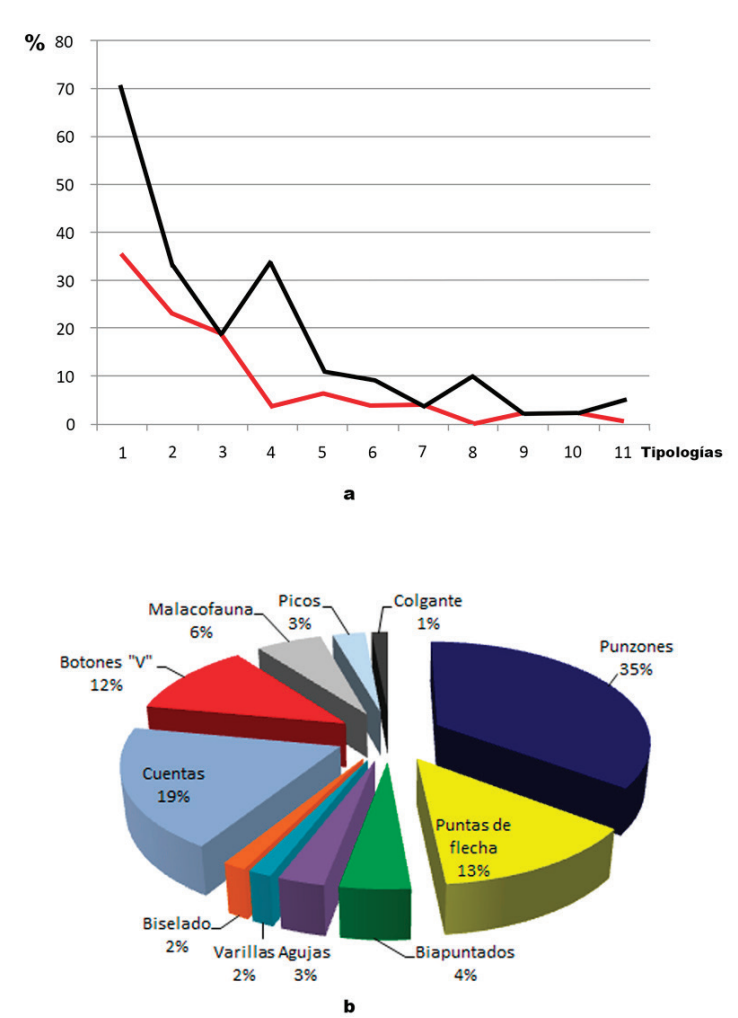

Fig. 4. La imagen superior (a) corresponde a las tipologías óseas distribuidas según su contribución en el Bronce antiguo (línea negra) y en el Bronce medio (línea roja). La abscisa representa las tipologías y la coordenada los \% de cada una de estas tipologías en el Bronce antiguo y en el Bronce medio. La imagen inferior (b) corresponde al \% de los diferentes tipos recuperados pertenecientes a la Edad del Bronce de forma conjunta.

\section{1. Útiles}

\subsubsection{Punzones}

Agrupa a más de la mitad de los apuntados, al reunir veinticuatro elementos. Estos objetos han sido elaborados sobre hueso, asta y diente. Atendiendo a caracteres morfotécnicos cabe distinguir seis tipos:

Punzones de economía. Integra a fragmentos y esquirlas con acondicionamiento exclusivo de la punta conformando cuerpos irregulares.

Se han recuperado cuatro elementos realizados sobre hueso (Tab. 2), en dos de los cuales no se ha podido determinación de la especie. Como datos morfológicos básicos destaca- 


\begin{tabular}{|c|c|c|c|c|c|}
\hline \multicolumn{6}{|c|}{ CLASIFICACIÓN DE LOS ÚTILES ÓSEOS } \\
\hline \multicolumn{3}{|l|}{ Bronce Antiguo } & \multicolumn{3}{|c|}{ Bronce Medio } \\
\hline Tipo & Subtipo & Soporte & Tipo & Subtipo & Soporte \\
\hline \multirow{7}{*}{ Punzónes (17 } & Economia [7] & $\begin{array}{l}\text { Hueso } 3 \text { (1 bóvido) } \\
\text { Asta (4) }\end{array}$ & \multirow{7}{*}{ Punzónes (7) } & Economia (1) & $\begin{array}{l}\text { Hueso (metápodo de } \\
\text { ovicáprido }\end{array}$ \\
\hline & $\begin{array}{l}\text { Base reservada } \\
\text { (2) }\end{array}$ & $\begin{array}{l}\text { Hueso ( } 1 \text { costilla de } \\
\text { equido y } 1 \text { ulna de } \\
\text { ovicaprido }\end{array}$ & & $\begin{array}{l}\text { Base reservada } \\
\text { (1) }\end{array}$ & $\begin{array}{l}\text { Hueso (escápula de } \\
\text { ovicaprido }\end{array}$ \\
\hline & Tubular (2) & $\begin{array}{l}\text { Hueso ( } 1 \text { de } \\
\text { ovicáprido, otro } \\
\text { indeterminado) }\end{array}$ & & Tubular (1) & Hueso \\
\hline & Hendido (2) & Hueso Ind. & & Hendido (2) & $\begin{array}{l}\text { Hueso ( uno sobre } \\
\text { costilla) }\end{array}$ \\
\hline & Facetados (2) & Hueso & & & \\
\hline & Diente (2) & Incisivos suidos & & & \\
\hline & & & & $\begin{array}{l}\text { Indeterminados } \\
\text { (2) }\end{array}$ & Hueso \\
\hline Picos (2) & & Asta & & & \\
\hline \multirow[t]{3}{*}{ Puntas de Flecha (10) } & Fusiformes (8) & $\begin{array}{l}\text { Hueso (7) } \\
\text { Asta (3) }\end{array}$ & & & \\
\hline & Lanceolada (1) & & & & \\
\hline & Palmela (1) & & & & \\
\hline \multirow[t]{3}{*}{ Blapuntados (3) } & & Hueso & Blapuntados (1) & & Hueso \\
\hline & & & Agujas (2) & & Hueso \\
\hline & & & Varilla (1) & & Hueso \\
\hline Biselado (1) & & Hueso & & & \\
\hline Cuentas (11) & Tubulares & Hueso & Cuentas (2) & Tubulares & Hueso (2) \\
\hline Botones " V" (2) & Prismáticos & Hueso & Botones "V" (6) & Prismáticos & $\begin{array}{l}\text { Hueso (S) } \\
\text { Marfil (1) }\end{array}$ \\
\hline Colgante (1) & & Hueso & & & \\
\hline Malacofauna (3) & & Malacofauna & Malacofauna (1) & & Malacofauna \\
\hline
\end{tabular}

Tabla. 2. Clasificación de los útiles óseos según tipos industriales con mención a la naturaleza del soporte para los casos contrastados.

mos uno de sección cóncavo-convexa, otro oval con su superficie quemada y el soporte en media caña sobre hueso posiblemente de un bóvido y un tercero que de nuevo presenta huellas de fuego en su superficie y evidencias de cocción ya que muestra un aspecto más terso y a veces vítreo, con una coloración más amarillenta y compactada que los que no han sido sometidos a este proceso (Botella et al. 1999). Por último contamos con un punzón de base apuntada y extremo distal muy pulido realizado sobre metápodo de ovicáprido (Fig. 5, a) (Tab. 2).

Sobre asta de cérvido se han identificado cuatro elementos (Tab. 2): uno de sección plana y superficies irregulares, dos ápices redondeados y quemados, y el último incompleto de extremo muy pulido (Fig. 5, b).

Punzones con base articular o reservada.
Dentro de la colección contamos con tres ejemplares (Tab. 2): uno sobre costilla de équido de sección poligonal con tendencia circular en la punta y con marcas de pulido intenso excepto en el extremo proximal (Fig.5, c); otro sobre ulna derecha de ovicáprido de la que sólo se abrasionó el extremo agudo, obteniendo una punta de gran resistencia; el único del Bronce medio está realizado sobre escápula derecha de ovicáprido (parte de la cavidad glenoidea) fuertemente pulida para su afilado distal.

Punzones sobre pieza dentaria. Los dos casos que nos ocupan fueron realizados sobre incisivos de suidos, cuyos ápices fueron biselados para obtener el apuntamiento distal (Tab. 2; Fig. 5, d).

Punzones tubulares sin base. Encajamos aquí tres elementos incompletos (Tab. 2): 
uno sobre diáfisis de radio de ovicáprido (Fig. 5, e) y dos sobre soporte no determinable.

Punzones hendidos. Obtenidos a partir de la diáfisis de los huesos largos. Presentan los bordes del fuste paralelos o suavemente convergentes y la cara ventral alisada. Con esta tipología se han podido identificar cuatro ejemplares: uno incompleto cuyo pulido afecta a la totalidad de la pieza, reduciendo la mayor parte del canal medular (Tab. 2; Fig. 5, f), un segundo caso correspondiente a un punzón realizado sobre una costilla de especie sin determinar, y dos más cuyas caras ventrales fueron menos trabajadas.

Punzones Facetados. De los dos ejemplares identificados (Tab. 2) uno se realizó sobre diáfisis de hueso largo, manteniendo una sección cuadrangular excepto en el extremo distal que es circular. Fue sometido a una intensa abrasión logrando un útil muy resistente (Fig. 5, g). El otro, sobre asta, es de base recta, bordes regulares y sección oval, con punta de sección circular (Fig. 5, h).

Punzones de tipología indeterminada.

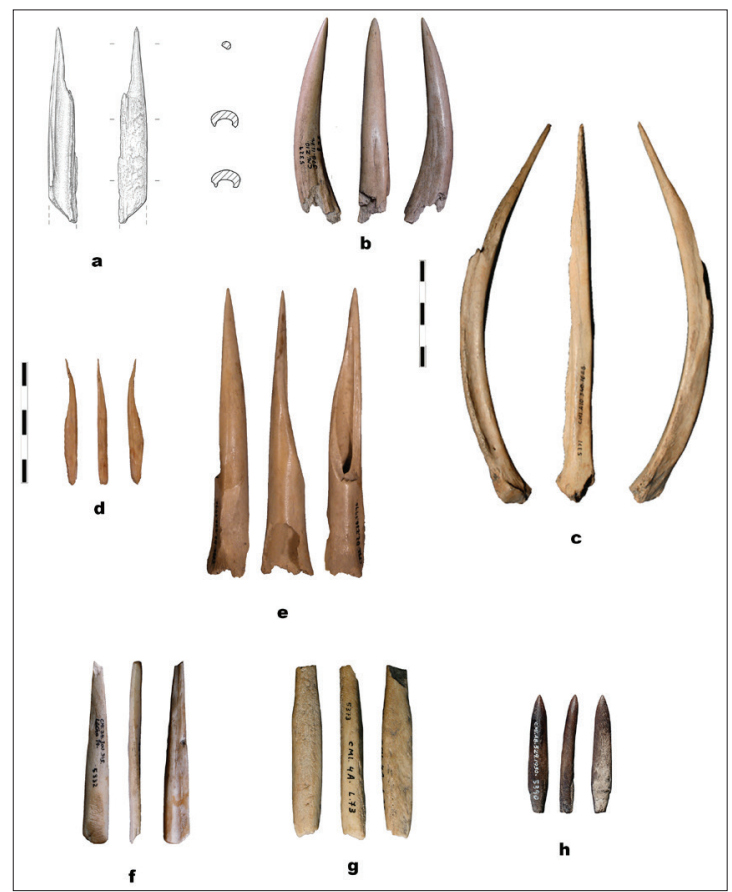

Fig. 5. Representación de cada uno de los tipos de punzones descritos en el texto. a y b.- punzones de economía; c.- de base articular; d.- sobre pieza dentaria; e.- tubular; f.- hendido; g y h- facetados. Los punzones $\mathrm{b}$ y $\mathrm{h}$ están realizados sobre asta, el resto sobre hueso.
Existen dos ejemplares realizados sobre fragmentos de diáfisis de hueso largo, posiblemente de ovicáprido, que no pueden encajarse dentro de tipos concretos al hallarse incompletos (Tab. 2).

\subsubsection{Picos}

Se trata de astas de cérvidos apenas elaboradas, de perfil acodado y cuya manipulación es un leve aguzamiento distal con escaso índice de penetración. En El Portalón dos piezas siguen este esquema (Tab. 2): una de ellas sobre asta de corzo de $145 \mathrm{~mm}$ de longitud y $45 \mathrm{~mm}$ de grosor (Fig. 6); la otra en asta de cérvido sin más precisión. Más allá de la convergencia en la clasificación tipológica se trata de elementos muy diferentes en dimensiones y formas y se ignora el uso real de los mismos.

\subsubsection{Puntas de flecha}

El conjunto de puntas de flecha recuperadas en los niveles del Bronce de El Portalón está compuesto

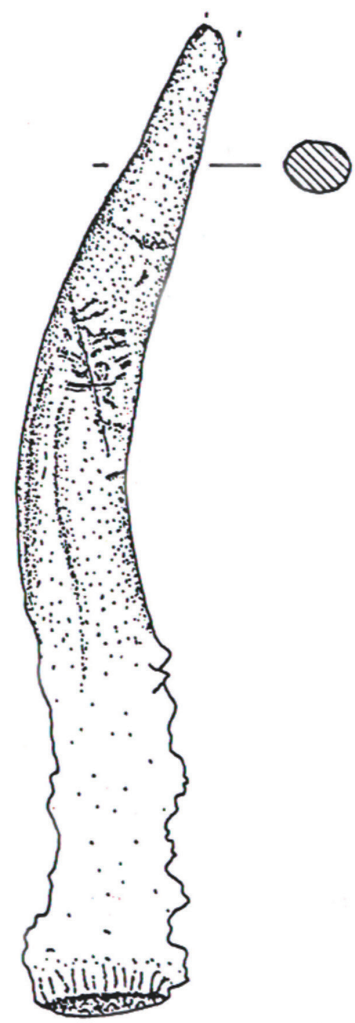

Fig. 6. Útil sobre asta de corzo correspondiente al Bronce antiguo. 


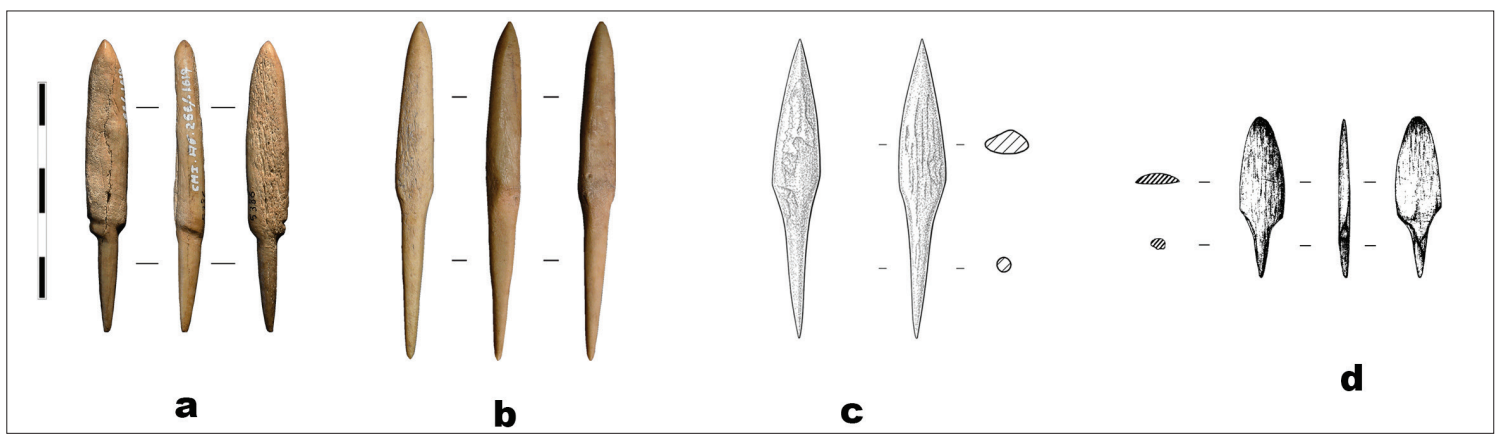

Fig. 7. Diferentes tipologías de puntas de flecha pertenecientes a la Edad del Bronce: a y b - tipo fusiforme; c.- tipo lanceolada y d - punta de flecha tipo "palmela".

por diez elementos (Tab. 2) con tres variantes representadas: siete fusiformes (Fig. 7, a y b), dos lanceolada (Fig. 7, c), y un ejemplar modelo "palmela" (Fig. 7, d). Hemos comprobado que siete son sobre hueso y tres sobre asta, estando dos en proceso de fabricación y una fracturada, siendo a menudo visibles intensos pulidos así como marcas de corte y de enmangue. Desde el punto de vista métrico estamos ante un conjunto heterogéneo: las longitudes oscilan entre los $84 \mathrm{~mm}$ y 24 $\mathrm{mm}$, si bien en anchuras, espesores y secciones la producción está más normalizada, así como en la proporción entre la longitud del cuerpo y del fuste (Tab. 2). En realidad el conjunto de puntas de flecha recogidas en las diversas actuaciones de campo suman veintisiete efectivos tratándose de la colección más densa de la península según consta en la bibliografía. Sin embargo, para la mayoría de ellas se desconoce con exactitud el contexto en el que se recuperaron. Es una producción bastante homogénea: dentro de la amplia variedad de tipos europeos, en Atapuerca solo se reconocen modelos lanceolados (5), ovales (2), fusiformes (15), triangulares (2), atípicas o no definibles (3), faltando otros tan clásicos como el de pedúnculo y aletas. Seguramente la mayor parte pertenecerán a la Edad del Bronce (inicial o medio) ya que la datación radiocarbónica de una de ellas (ATP'02 2) ha ofrecido un valor acorde con lo esperado para el Nivel 5 correspondiente al Bronce antiguo y para la contextualización de un grupo tipológico que en la península carecía de dataciones absolutas: Beta $2694923630 \pm 40$ BP (4080- 4030 cal BP).

\subsubsection{Biapuntados}

Dentro del conjunto de los biapuntados se han reconocido cuatro piezas de aspecto losángico.
Uno descentrado y alargado, posiblemente sobre costilla de ovicáprido, con bordes redondeados y significativos brillos de uso (Fig. 8, a). El segundo, alterado por procesos posteposicionales o quizá en proceso de fabricación (Alday et al. 2011)

Un tercer ejemplar corresponde a un objeto biapuntado con tendencia losángica asimétrica que alcanza los $7,8 \mathrm{~cm}$ de longitud por 0,85 de anchura siendo su sección plana. Su estado general y la presencia de brillos pone de manifiesto el carácter antrópico de la pieza: no se descarta que abrasiones $u$ otros procesos posteposicionales hayan otorgado la forma definitiva al objeto.

El último caso corresponde a un objeto realizado en hueso, de planta romboidal alargada y de sección circular con característico estrangulamiento central mediante dos pequeñas muescas opuestas (Fig. 8, b). En otra publicación (Alday

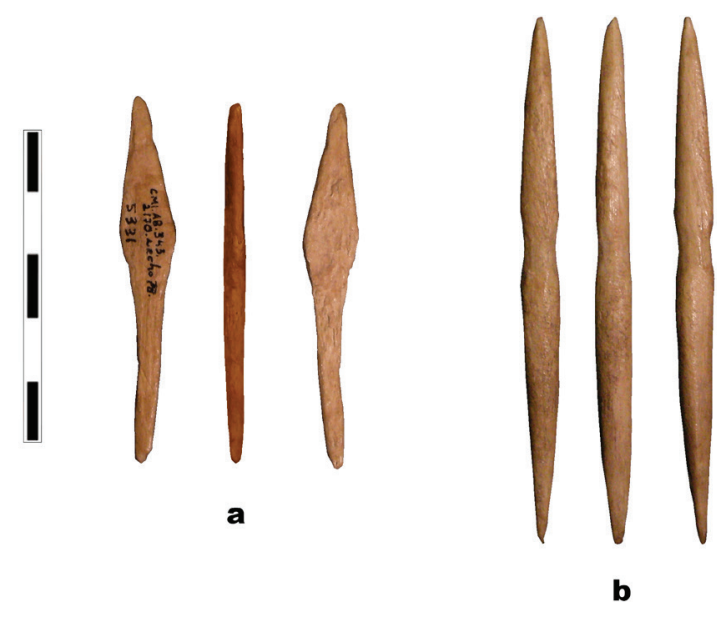

Fig. 8. Dos ejemplos de útiles biapuntados recuperados en las excavaciones de G. Clark y J. M. Apellániz. 
et al. 2011) ya se ha especulado sobre su utilidad como anzuelos apoyándonos en sus caracteres morfológicos y en opiniones ajenas para útiles similares.

\subsubsection{Agujas/alfileres}

Se han recuperado dos agujas decorativas sobre hueso en El Portalón (Tab. 2). Se trata de objetos con unas similitudes tipológicas y morfológicas tan evidentes que no aportan ninguna duda sobre su pertenencia a un mismo conjunto. Son piezas con una cuidada elaboración, largas $(230 \mathrm{~mm}$ y $190 \mathrm{~mm}$ ), de sección oval finamente pulidos, extremo perforado y parte del fuste adelgazado respecto a la cabeza (Fig. 9, a y b).

\subsubsection{Varilla}

Objeto fino y apuntado de sección redondeada de $65 \mathrm{~mm}$ de largo por $5 \mathrm{~mm}$ de grosor. Los bordes laterales son paralelos salvo en una pequeña zona distal. Se trata de una pieza con alta transformación ya que su soporte se ha modificado por completo, al igual que sus huellas de elaboración que han sido borradas por un intenso pulido en la fase final (Tabla 2, Fig.9, c).

\subsubsection{Biselado/bruñidor}

Útil sobre hueso cuyos tramos distal y medial fueron pulimentados de forma intensa, y sus bordes cuidadosamente biselados (Tabla 2; Fig. 10).

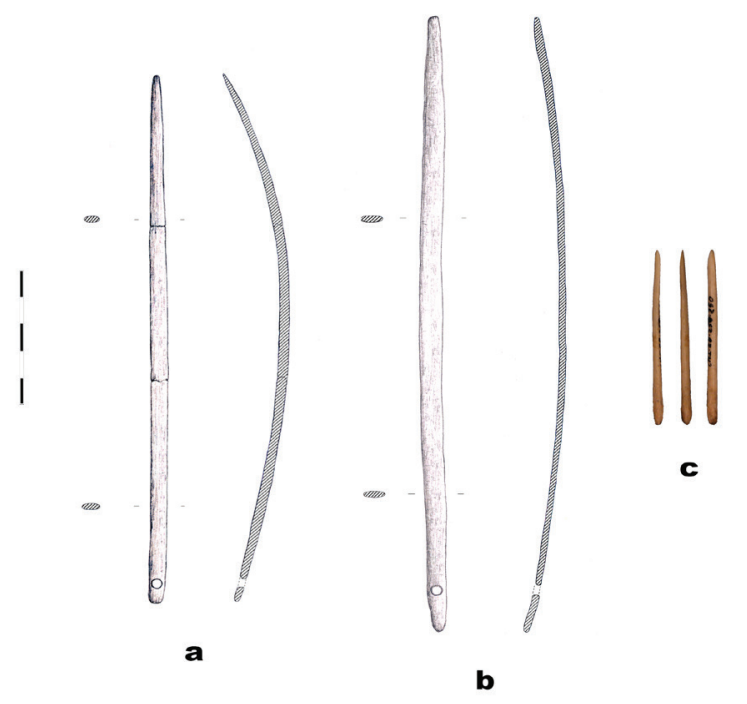

Fig. 9. A y b.-Agujas/ alfileres decorativas y c.- varilla recuperadas en El Portalón.

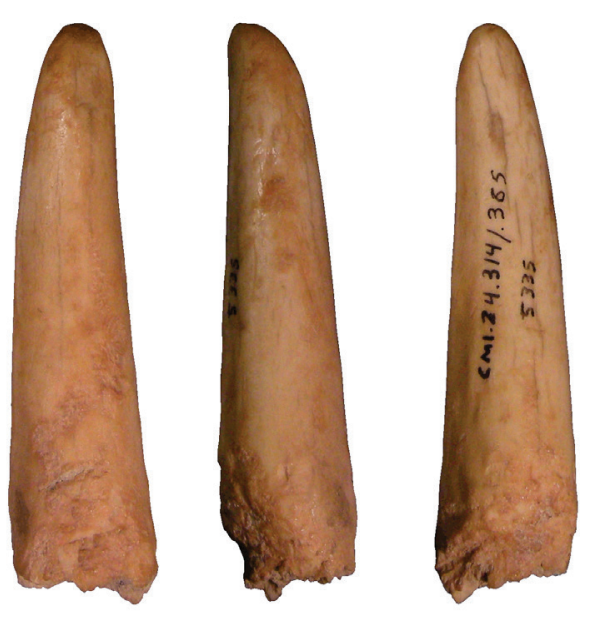

Fig. 10. Biselado/Bruñidor sobre hueso.

\subsection{Objetos de adorno}

\subsubsection{Cuentas}

Han sido documentadas 13 cuentas (11 del Bronce antiguo y 2 del Bronce medio) que conforman un grupo muy homogéneo aunque presentando las habituales variaciones morfológicas, que suelen estar relacionadas con la forma natural del hueso: troncocónicas (Fig. 11, a) cilíndricas (Fig. 11, b) y discoidales (Fig. 11, c). Las dimensiones, que oscilan entre los 27,50 mm las más largas a los $15 \mathrm{~mm}$ las de menor longitud, reproducen los parámetros dimensionales de este tipo de adornos en la Alta Cuenca del Ebro (Alday 1987). Del conjunto, al menos 5, por ubicación espacial en el interior de la cavidad y características morfométricas, pudieron pertenecer a un adorno complejo (Fig. 11, d).

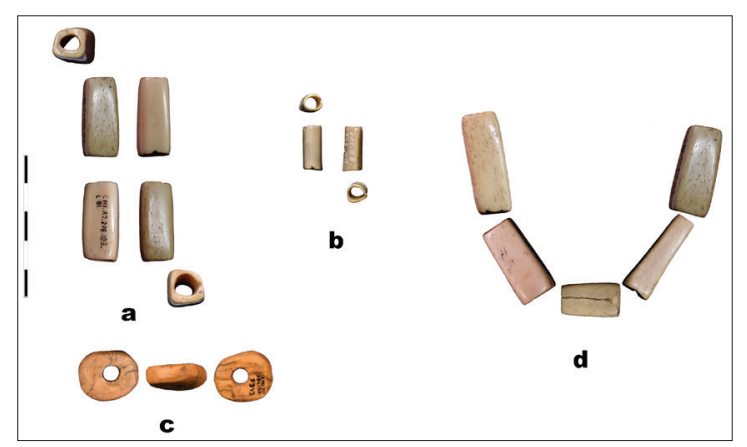

Fig. 11. Cuentas: a.- facetada; b.- cilíndrica c.discoidea y d.- conjunto de cuentas formando un adorno complejo 


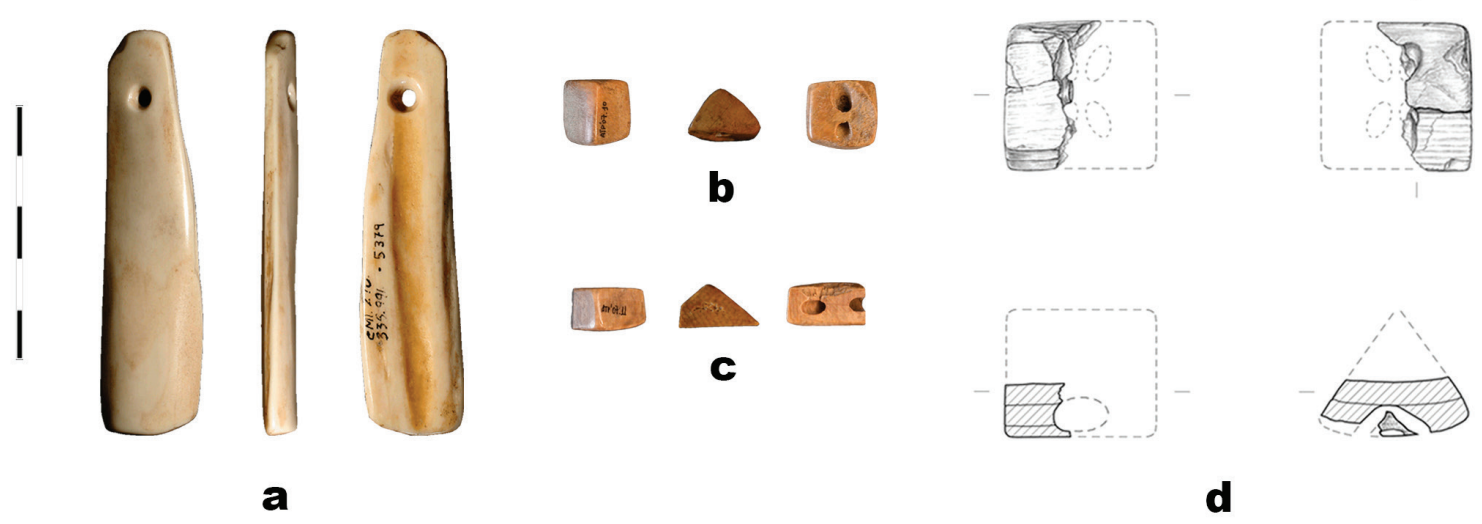

Fig. 12. a.- Colgante sobre hueso indeterminado; b.- botón primatico de hueso correspondiente al Bronce antiguo; c.- botón primatico de hueso correspondiente al Bronce medio y d.- botón prismático elaborado en marfil (Bronce medio).

\subsubsection{Colgante}

En las excavaciones practicadas en El Portalón solo se ha recogido una pieza realizada en hueso y trabajada en forma de colgante. Presenta morfología paralelepípeda, con el extremo basal redondeado y pequeña perforación distal cuidadosamente trabajada con un pulido muy cuidado que le aporta brillo a la pieza. (Tab. 2; Fig. 12, a).

\subsubsection{Botones de perforación en " $V$ "}

Los botones de perforación en $\mathrm{V}$ constituyen un artículo de amplia distribución geográfica y aunque aparecen vinculados al Campaniforme, desbordan ampliamente su espacio geográfico a lo largo del III y II milenio BC (López 2006). Si bien en la península suelen presentarse en agrupaciones llamativas, en la Meseta Norte las refe- rencias son escasas. A la primera fase del Bronce de El Portalón le corresponden dos ejemplares de morfología prismática y realizados en hueso (Tab. 2; Fig. 12, b). Por su parte son seis los ejemplares adscritos al Bronce medio, cinco realizados en hueso y uno de marfil (Tab. 2; Fig. 12 c y d), donde sorprende en primer lugar, su restricción formal ya que solo se conoce el modelo prismático, arquetipo que ofrece, a nivel europeo, una variación amplia en tamaños, disposición y número de perforaciones, siendo los de El Portalón los más sencillos y habituales.

\subsubsection{Malacofauna}

La presencia de malacofauna marina, cuando el Portalón dista unos 100 kilómetros del Cantábrico, señala el interés de la comunidad por mantener lazos con grupos lejanos. Hemos registrado tres elementos adscritos a la Edad del Bronce

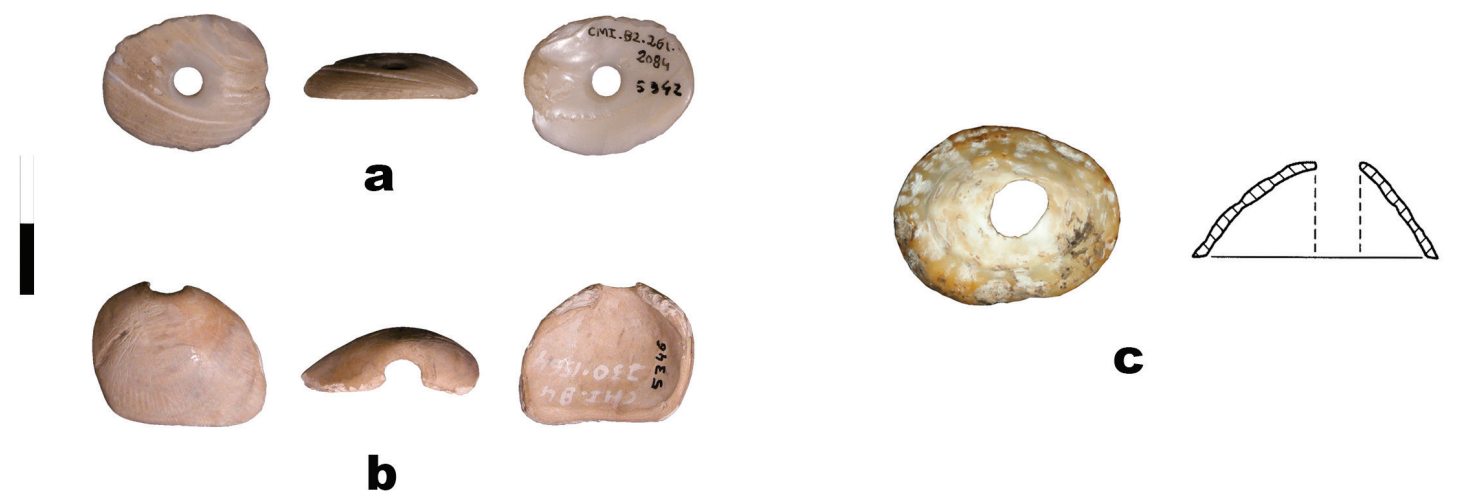

Fig. 13. Malacofauna: a.- cuenta discoidal realizadas en una Patella; b.- una concha con orificio central y c.- con perforación apical irregular de la que no podemos evaluar su origen. 
antiguo por uno del medio (Tab. 2): una Patella con amplia perforación central obtenida mediante abrasión (Fig. 13, a); otra más con perforación apical irregular de la que no podemos evaluar su origen por organismos litófagos, erosión marina o acto antrópico (Fig. 13, b); una concha también con orificio central (Fig. 13, c) y un fragmento de concha sin identificar y que, en realidad, no presenta ninguna transformación.

En lo referente a los procesos tecnológicos abordados para la realización del conjunto de la industria ósea, cuya lectura está seriamente comprometida por la propia manufactura, revelan que entre los apuntados el uso de bases epifisiales de huesos largos (tibias y ulnas) algunos presentan marcas oblicuas en la pared cortical resultado de cortes y aserrados longitudinales -trazas generalmente eliminadas en la fase de abrasión-. También hemos documentado cortes transversales en diáfisis de huesos largos, suavización de sus bordes y eliminación del tejido esponjoso en el caso de las cuentas tubulares. La flexión y la percusión debieron ser empleadas en la manufactura de algunos útiles como los apuntados. Por último, la perforación ha sido constatada en la elaboración de cuentas sobre concha y en las agujas. Insistimos que solo hemos abordado una aproximación sobre los procesos de fabricación de los útiles de nuestro trabajo, sabiendo que una reflexión más profunda de la cadena operativa necesita un adecuado control de las matrices, las esquirlas, las operaciones practicadas, la detección y explicación de los estigmas, etc.

\section{Discusión}

El inventario óseo de la Edad del Bronce de El Portalón, encuentra similitudes en yacimientos que le son contemporáneos, algunos ubicados con tal proximidad geográfica que no puede dudarse que este territorio conforma una misma unidad cultural. No puede ser casual, por ejemplo, las semejanzas entre el Portalón y Cueva Lóbrega, en cronologías, usos e inventario material, especialmente en cuanto a sus objetos sobre hueso (Barrio et al. 2004). En otros casos las distancias por recorrer son tan extensas que sugieren intercambios en unas sociedades donde el prestigio era moneda corriente. Además hay que pensar en la presencia de artesanos especialistas, particularmente para aquellos cuyas bases materiales requerían alguna habilidad, como es el caso del marfil, o de la extracción de largas y finas varillas para fabricar agujas/alfileres o como parece ocurrir en El Portalón, para la fabricación del conjunto de puntas de flecha recuperadas en la cueva.

El inventario óseo de las dos fases culturales pertenecientes a la Edad del Bronce es bastante homogéneo (Tab. 2) si bien se observa en el paso de una a otra un descenso del utillaje y, en consecuencia una restricción de la variabilidad en tipos y subtipos. No podemos descartar que se trate de un simple sesgo fortuito del registro, pero nos inclinamos a pensar que refleja la diferente contribución de esta artesanía por niveles. Por ejemplo, no hemos reconocido asta de ciervo en los horizontes del Bronce medio, cuando representa el $22 \%$ de los soportes en la fase anterior y, entre las piezas de hueso, hay solamente una identificada sobre hueso de ovicáprido en el Bronce medio que contrasta con la variedad propia del Bronce antiguo (bóvidos, équidos y suidos).

Los punzones son unos de los elementos más habituales y menos exigentes en su elaboración dentro de los inventarios óseos postpaleolíticos. Como resultado no es difícil hallar paralelos para cada una de sus variantes. A pesar de ello, y teniendo como único objetivo visualizar la colección de El Portalón dentro de un conglomerado cultural complejo y diverso como el de las primeras edades de los metales, queremos resaltar algunos casos bastante próximos en lo geográfico y en lo cultural. El más cercano el abrigo de El Mirador, en la misma sierra de Atapuerca, de nuevo una cueva que combinó el encierro del ganado con expresiones funerarias (Vergès 2002) y de donde provienen dos apuntados similares a los de El Portalón. Para la variante "de base reservada" interesa recordar los punzones rescatados en los recintos funerarios de Pico Ramos (Bizkaia) (Zapata 1995), los siete elementos de Las Yurdinas II (Álava) (Fernández Eraso 2003) que guardan semejanzas en forma y medida con los de El Portalón y los de Las Arnillas, La Cotorrica y La Cabaña (Burgos) (Delibes et al. 1986). Al respecto resulta llamativa la ausencia de punzones en el megalitismo vasco cuando sí aparecen en estaciones burgalesas. Por su parte, el modelo hendido encuentra una amplia distribución, tal y como evidencia el inventario confeccionado por Rodanés (1987) para la Cuenca del Ebro. Nos interesa rescatar el lugar de Los Husos, porque, además de los punzones comparte con El Portalón los botones de perforación en "V", y ambos lugares formalizan una red de establecimientos que, entre otras cosas, sirve para la gestión de un ganado que se desplaza por las sierras y se esta- 
bula en grandes covachas y cuevas (Verges et al. 2002). Por lo mismo, al compartir la lógica de las ubicaciones y sus funciones, tampoco queremos pasar por alto el depósito de La Vaquera (Segovia), en cuya colección ósea hay abundantes y variados punzones (Estremera 2003).

Junto a estos modelos de punzones, de cuyas convergencias formales no sabemos cuánto se deben al azar, se añaden los ejemplares de fortuna, que como otros muchos carecen de capacidad diagnóstica en lo cultural, pero que evidencian lo importante que era para estas sociedades contar con un utillaje apuntado cuya fabricación, nada exigente, podía hacerse de inmediato y sin selección de la base material específica que sirva de soporte. En cualquier caso se impone una reflexión de cierto interés. En la lista de lugares que hemos ido citando, predominan los contextos funerarios, pero la prevalencia de estos frente a los de habitación puede dar una imagen errónea de la consideración de la industria ósea en general, y de los punzones en particular: ¿Pertenecían a un ajuar de acompañamiento a los difuntos fabricados ad hoc?, ¿eran objetos de uso doméstico abandonados una vez terminada su vida útil?, ¿el apuntamiento que los define evidencia su uso en labores punzantes o estos objetos pudieron tener otro destino (presillas de vestimenta,...)? Estas cuestiones nos deben de poner en aviso frente a ejercicios comparativos como el que acabamos de hacer. Por otra parte, no hay que insistir en que siendo útiles simples y con tan amplia tradición no hay, menos en esta región, una norma en su evolución tecnomofológica. Solo queremos llamar la atención sobre la gran acumulación de ejemplares en El Portalón, que supera a los hallados en contextos sedimentológicos similares.

En esta línea, la presencia en El Portalón de picos a partir de simples manipulaciones de astas de cérvidos no resulta sorprendente cuando se han citado también en contextos similares como Los Husos (Alava) (Apellániz 1974) y Cueva Lóbrega (Barrios et al. 2004).

Respecto a las puntas de flecha tampoco es fácil cotejar la producción de El Portalón con las de otros yacimientos cercanos como son los casos alaveses de Solacueva de Jócano (Llanos 1991), Los Husos y El Sotillo (Apellániz 1974) y los riojanos de Cueva Lóbrega (Ceniceros y Barrios 1988) y la Atalayuela (Barandiaran 1978) (Fig. 14). Muy probablemente el origen de estas puntas óseas hay que buscarla en las precedentes Calcolíticas elaboradas en sílex y, más directamente, en las metálicas que les son contemporáneas y de las que quizá fueran réplicas (ver Kaiser 2004): al respecto son muy destacables las semejanzas formales entre el ejemplar de Arenaza y una de las de El Portalón con piezas metálicas recuperadas en los dólmenes de Obioneta y Ausokoi. La amplia distribución de las puntas óseas en la península ha permitido diseñar una serie de influencias e intercambios internos y externos (en este caso proponiendo vías de llegada similares a la de varios de los elementos de la cavidad). Sin descartar algún estímulo externo, en un ambiente de interés hacia los objetos óseos, pensamos que las de El Portalón encajan mejor con la idea de una elaboración propia, de ahí su homogeneidad morfológica. Quizás un remedo más gestual que práctico -no las hay con el extremo distal roto, por más que algunas estén deterioradas- frente a la nueva tecnología de la metalurgia, más cara y de difícil acceso, pero susceptible de plagiarse.

Los biapuntados que hemos registrado en el conjunto de las dos unidades de la Edad del Bronce presentes en el Portalón no responden exactamente a las mismas variantes ni usos. Algunos paralelos contemporáneos con similares métricas se han citado en los refugios de los Husos (Álava) (Apellániz 1974), Moro de Olvena (Huesca) (Rodanés 1995) o Nerja (Málaga) (Aura y Pérez 1998) (Fig. 14). Para aquellos con el característico estrangulamiento mesial, los especialistas discrepan sobre sus posibles funcionalidades. Autores como Barandiarán (1967), Cheyner (1967) o Averbouh et al. (1995) los han relacionado con actividades de pesca, idea que encuentra apoyos en ejemplos etnográficos nórdicos y siberianos. Fuera del escenario peninsular las referencias sobre biapuntados prehistóricos de posible relación con la pesca son, en general, poco explícitas, así que interesan vivamente los ejemplares suizos estudiados por Voruz (1987) y Averbouh (1995), o los nórdicos, como por ejemplo del sitio de Ajvide (Alday et al. 2011). Quizá la sorpresa inicial que puede causar la referencia a casos centroeuropeos quede atenuada al observar lo que ocurre con las agujas/alfileres decorativos de la cavidad burgalesa: sus paralelos han sido rastreados en Cueva Lóbrega (La Rioja) y en el dolmen de Sakulo (Navarra) (Fig. 14), fronterizo con Francia y en lugares europeos del corredor Ródano-Rin, el noroeste de Italia y Suiza (Barge 1982; Delibes y Fernández 1983; Camps-Fabrer y Ramseyer 1990). Esta agujas parecen haber sido fabricadas bajo cánones similares a las agujas de à belier, habituales en estas mismas regiones y cuyos representantes más meridionales se encuentran en 


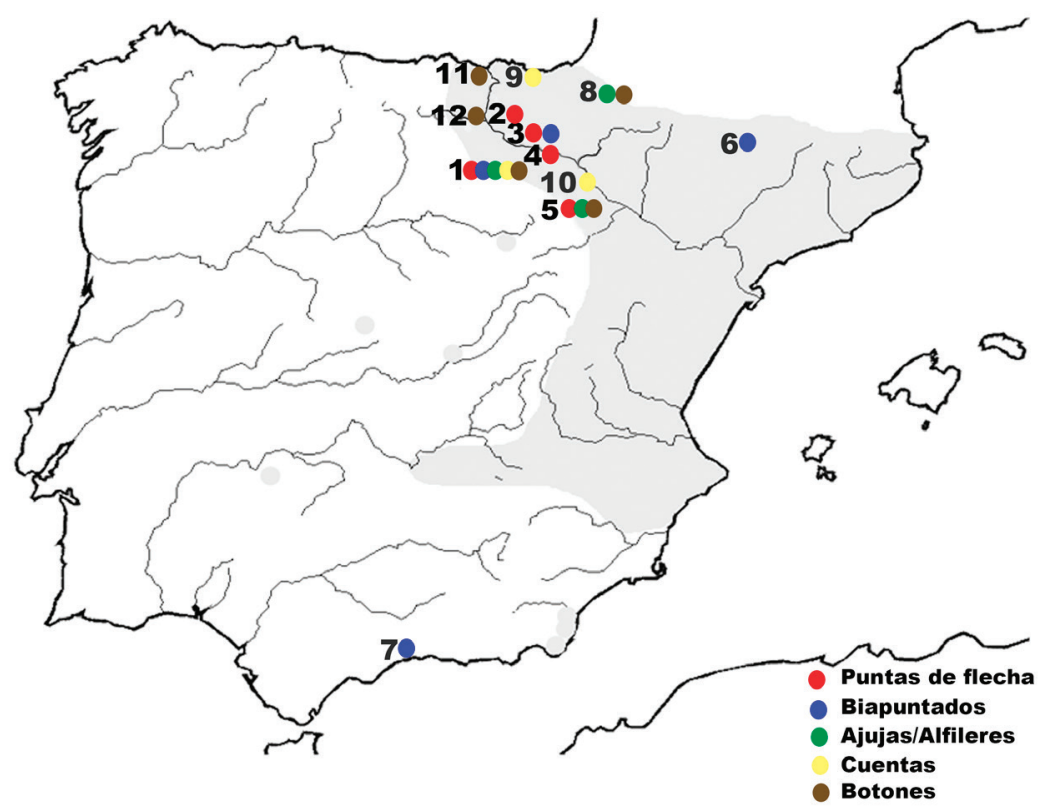

Fig. 14. Distribución de los principales yacimientos mencionados en el texto: 1) Atapuerca (Burgos); 2) Solacueva (Jocano, Álava); 3) Los Husos (Elvillar, Álava); 4) El Sotillo (Álava); 5) Cueva Lóbrega (Torrecilla de Cameros, La Rioja); 6) Moro de Olvena (Huesca); 7) Nerja (Málaga); 8) Sakulo (Navarra); 9) Kobeaga (Bizkaia); 10) Peña Guerra (La Rioja); 11) Pico Ramos (Bizkaia) y 12) Covairada (Álava). La zona gris corresponde a al territorio donde las puntas de flecha aparecen con más profusión (Fernández 1998).

los sepulcros ibéricos de La Atalayuela (La Rioja) y Tres Montes (Navarra) (Andrés y Barandiarán 2004; García y Sesma 2007).

Respecto a las cuentas tubulares es necesario recordar que no son piezas especialmente singulares pero tampoco productos muy frecuentes en registros arqueológicos como el presente, pues lo normal es su hallazgo en contextos funerarios. Como referencias cercanas necesarias por la proximidad morfométrica de los ejemplares y por su concentración, cabe destacar el ajuar de la cueva sepulcral de Kobeaga (Bizkaia) con diecinueve cuentas y fragmentos de otras cinco que junto a otros elementos bien pudieron constituir un adorno complejo asociado a la única persona inhumada (Apellániz y Nolte 1966). También es significativo el dolmen de Peña Guerra I (La Rioja) con un conjunto amplio de cuentas algo menores que las recuperadas en El Portalón, junto a otras similares sobre piedra (Pérez y López de la Calle 1986) (Fig. 14). Merece la pena resaltar también dentro del ajuar de este megalito la presencia de otras piezas cercanas a El Portalón: una Patella perforada, trece colgantes óseos complejos y seis fragmentos distales del Dolmen de Peña Guerra I objetos, estos últimos, que pre- sentan semejanzas con cuatro ejemplares de Kobaederra (Bizkaia) (Zapata et al. 1997), tal vez algo menos elaborados.

Es bien conocido que los botones piramidales $\mathrm{y}$ prismáticos de perforación en $\mathrm{V}$ ofrecen una concentración llamativa en los Pirineos orientales y el Quercy francés, estando los paralelos más cercanos a El Portalón en los dólmenes de Las Arnillas (Burgos) (Delibes et al. 1986), Zeontza y Sakulo (Navarra) (Maluquer de Motes 1963), y en las cavidades de Los Husos (Alava) (Apellániz 1974), Cueva Lóbrega (La Rioja) (Barrios et al. 2004) y Pico Ramos (Bizkaia) (Zapata et al. 1997) (Fig. 14).

Mención especial en este apartado supone la presencia de un botón fabricado en marfil (ATP'07 9) (Tab.2; Fig. 12, d), que presenta una conservación general no muy buena por alteraciones postdeposicionales con evidentes signos de exfoliación. Lo clasificamos dentro de los tipos prismáticos ya que las propias características del marfil inclinan al desarrollo de esta morfología, y no otra (Barciela 2002). Dado su estado fragmentario no podemos concretar el origen de su base, aunque la presencia parcial del agujero nutricio pareciera indicar que su soporte fuera colmillo 
de jabalí, pero no es este argumento definitivo. Por otra parte, su estado impide la distinción de líneas de Schreger, no concretándose así que el marfil proviniera de alguna especie de elefante. Botones de similar soporte se han descrito tanto en contextos funerarios como domésticos de yacimientos cercanos al nuestro: Covairada (Álava) (Barandiarán 1964), Pico Ramos (Bizkaia) (Zapata et al. 1997) y Sakulo (Navarra) (Maluquer de Motes 1963).

Hay que recordar que en regiones más meridionales y orientales de la península es frecuente la presencia de este material, entendiendo su hallazgo en El Portalón dentro de un contexto donde la ostentación (López Padilla 2009), los elementos de lujo o de prestigio son habituales, planteando la existencia de desigualdades sociales también entre las poblaciones meseteñas de la Edad del Bronce (Delibes et al. 2000; Delibes y Val 2007-2008; Carmona et al. 2010).

Se entienden los objetos sobre marfil, sea a la manera de botones, placas o brazaletes, como evidencia de relaciones sociales de gran amplitud geográficas (Barciela 2006). En los últimos años se ha revitalizado su estudio en contextos arqueológicos (Garcia Sanjuan 2013) enfocando bastante de los esfuerzos en la concreción de la naturaleza del soporte. Se ha comprobado su procedencia de elefantes asiáticos y africanos, e incluso del extinto Elephas antiquus (por ejemplo de las terrazas del Manzanares) (Liesau 2011-12) o del cachalote en contextos litorales de Portugal (Schuhmacher 2013; Schuhmacher y Banerjee 2012). Los datos sustentan la importancia de las relaciones entre África y Europa y, en el caso de El Portalón, podrían insinuar interacciones con grupos afincados mucho más al sur ¡no todo iban a ser relaciones hacia el norte, o por el Valle del Ebro, incluso hasta el Mediterráneo como sugieren varias de las conchas recuperadas! En realidad, siempre hemos sospechado que, al menos desde el Calcolítico, los intercambios eran multidireccionales siguiendo diversos caminos, si bien la documentación arqueológica tendía en nuestra región a enfatizar unas rutas frente a otras. No olvidemos, como añadidura, que los inventarios de El Portalón se registran cerámicas campaniformes y útiles de metal de estilos meseteños o que la propia red de apriscos, como El Portalón, demuestra una comunidad de intereses en amplias geografías (Anderung et al. 2005). En el caso del marfil de las tierras meridionales de la península se especula con que su distribución refleja jerarquización territorial y desarrollo de talleres (Vargas et al. 2012) o, para el caso de El Acequión (Fernández et al. 1994). En nuestra región estamos aún lejos de poder definir rangos en el conjunto de yacimientos de las primeras edades del metal, aunque sabemos que las actividades desarrolladas en la cavidad se incardinan en un conjunto de estrategias sociales y económicas donde la ganadería juega un papel fundamental $\mathrm{y}$ en donde los intercambios revelan tejidos sociales bien hilvanados (más allá de intercambiar objetos).

\section{Conclusiones}

La secuencia estratigráfica del yacimiento del Portalón es muy compleja, tanto por su prolongada ocupación (del Pleistoceno Final a la Edad Media), como por las actividades y los usos diferenciados, de habitación, estabulación, y rituales, llevados a cabo en su interior. Aquí analizamos los objetos óseos adscritos a la Edad del Bronce. En esta cultura hubo un desarrollo importante de la actividad pastoril, acudiendo a las sierras en busca de pastos y utilizando las cuevas, como es el caso de la entrada de Cueva Mayor, para encerrar el ganado. Un amplio abanico de fechas absolutas de los niveles 3 a 5 de El Portalón, señala una continuidad habitacional durante de la Edad del Bronce antiguo y medio entre el 3700 y el 3300 BP. Cuatrocientos años en los cuales la cavidad sirvió de refugio de pastores, con caracteres sedimentarios que se adecuan al perfil de un fumier y donde otras tareas domésticas, de caza e incluso rituales fueron comunes. La densa ocupación, que ha dejado un relleno de en torno a metro y medio de potencia, ha legado un importantísimo inventario cerámico (a mano, preferentemente reductora, con abundancia de formas carenadas, terminaciones lisas o bruñidas y decoraciones a base de mamelones, cordones y digitaciones), de industria lítica (de base laminar donde destacamos las piezas de hoz), de industria ósea (de la cual hablamos en este trabajo) o de objetos metálicos en menor medida.

La fauna recuperada revela una importante presencia de animales domésticos con cuatro especies para consumo, más el perro, documentándose también la caza de animales salvajes. Este conjunto faunístico procuraba al grupo una amplia variabilidad de soportes óseos que manipular. Huesos, astas y dientes sirvieron para la confección de útiles variados en forma y destinos. Las cualidades de la materia condicionan los trabajos, 
encontrando binomios del tipo costillas-agujas, huesos largos-punzones, dientes-micropunzones y conchas-colgantes.

La muestra ósea está compuesta por un variado abanico de tipos que van desde el hueso poco elaborado hasta piezas que, como los botones de perforación en "V", exigen un complejo trabajo y siguen esquemas tecnotipológicos muy ajustados y reconocidos en una amplia geografía. Hay evidencias de manufactura in situ de algunas piezas, pero es bien posible que otras, más específicas como los largos alfileres decorativos, hayan llegado por intercambios. Buena parte de los artefactos apuntados presentan una mínima transformación del soporte natural, conservando parte de sus rasgos anatómicos distintivos (diáfisis, canal medular, epífisis, etc.). Por otra parte, las puntas de flecha y los objetos de adorno presentan un acabado formal cuidado, modificando de forma notable la morfología original del soporte para obtener la forma deseada y el pulido de las superficies.

Respecto al estado de conservación, destaca el elevado porcentaje de piezas completas frente a las que aparecen fracturadas. Los huesos más frecuentes utilizados son de ovicápridos y en menor medida de bóvidos, équidos y cérvidos. Parece haber una correspondencia entre el porcentaje de especies animales consignadas entre la fauna y el origen de los soportes.

La variedad tipológica del inventario traduce usos muy diversos. Una parte probablemente para labores domésticas (alfarería, tratamiento de pieles, costura, etc.), otra como armamento (creemos que éste fue el destino de las puntas de flecha) y una significativa para adornarse (cuentas, colgantes, botones...). Normalmente en el registro arqueológico estos últimos se vinculan a recintos funerarios. En El Portalón se han hallado restos humanos dispersos que no han podido relacionarse con estos objetos pero que en cualquier caso desvelan cierto compromiso social.

Hay una evolución interna en la artesanía sobre hueso de El Portalón: dos tercios de la producción corresponde a la fase antigua del Bronce, el otro tercio a la media, dato aún más elocuente si tenemos en cuenta que el nivel más antiguo, el 5 , es menos espeso que los más recientes, 3 y 4 obviamente es una dinámica que deberá relacionarse con las actividades realizadas en la cavidad en cada momento. En esta situación es bueno fijarse en algunos de los tipos reconocidos en la cueva. Los punzones suponen un tercio de la colección, llamando la atención que casi la mitad de los del Bronce antiguo son del tipo fortuna/economía, es decir, que son producciones inmediatas, para realizar actividades que surgen en el momento y que necesitan de un instrumental punzante. Este tipo no se ha localizado en el Bronce medio. Todas las puntas de flecha son de la fase antigua, quizá este hecho otorga más fuerza a la hipótesis sobre su significado como réplica de los modelos metálicos y una vez afianzada la metalurgia sus imitaciones desaparecen. También son exclusivos de estos momentos los alfileres decorativos (ajustándose cronológicamente a sus paralelos centroeuropeos) y las cuentas tubulares (El Portalón ayuda a situar las halladas en los contextos abiertos de los megalitos). En contra, los botones prismáticos de perforación en $\mathrm{V}$ se vinculan al Bronce medio, incidiendo en la idea de que suponen el punto final de la evolución de estas presillas, si bien su uso se prolonga más allá de estas fechas.

Al rastrear en diversos contextos arqueológicos contemporáneos utensilios óseos de características similares a los de El Portalón, lo que se ha evidenciado son las relaciones que el grupo asentado en la cavidad mantiene con otras sociedades. En estos momentos, la propia génesis del yacimiento responde al interés socio-económico de crear una red de apriscos serranos en un contexto de florecimiento de las prácticas agrícolas y ganaderas. Hay por tanto, movimientos territoriales que afectarían a las personas, al ganado (Anderung et al. 2005), a los materiales de diferente naturaleza (vemos conexiones con la Meseta, el sur-sureste peninsular, el Alto y Medio Ebro, los Pirineos, la fachada atlántica francesa o el Valle del Ródano...) y también a las ideas. Esta lectura derivada del utillaje óseo consolida la importancia de El Portalón de Cueva Mayor de Atapuerca. $\mathrm{Su}$ vitalidad y potencia está ligada a un entramado cultural entre cuyas manifestaciones están los emblemáticos poblados. 


\section{Agradecimientos}

Nuestro más sincero agradecimiento a los compañeros del laboratorio de Evolución Humana de la Universidad de Burgos, en especial, a Laura Rodríguez, Rebeca García, Elena Santos y Eneko Iriarte, así como al equipo de excavaciones del Portalón y de los yacimientos de la Sierra de Atapuerca. Agradecemos la colaboración prestada por Marta Negro, directora del Museo de Burgos, por las facilidades prestadas para la consulta de los materiales del Portalón allí depositados. Esta investigación ha sido financiada por el Ministerio de Educación y Ciencia proyecto $n^{\circ}$ CGL 2009-08938-C03-03, CGL 2012-38434-C03-01 y HAR201126364. Las excavaciones de Atapuerca son financiadas por la Consejería de Educación y Cultura de la Junta de Castilla y León.

Marian Galindo-Pellicena disfruta de una ayuda a la investigación de la Fundación Atapuerca.

\section{REFERENCIAS BIBLIOGRÁFICAS}

Aldán Álvarez, G.E. (2013): Producciones óseas funcionales y decorativas. Métodos y técnicas de análisis y estudio en arqueología prehistórica. De lo técnico a la reconstrucción de los grupos humanos (M. García-Diez, L. Zapata, eds.). Servicio Editorial de la Universidad del País Vasco.

Alday, A. (1987): Los elementos de adorno personal y artes menores en los monumentos megalíticos del País vasco meridional. Estudios de Arqueología Alavesa, 15: 103-353.

Alday, A.; Juez, L.; Pérez Romero, A.; AdÁn, G.E.; Santos, E., M.; Galindo-Pellicena, M.A.; Carretero, J.M.; Arsuaga, J.L. (2011): La industria ósea de El Portalón de Cueva Mayor (Sierra de Atapuerca, Burgos): Biapuntados, puntas de flecha y agujas, morfología y funcionalidad. Munibe, 62: 27-249.

Altamirano, M. (2011): Worked bone industry from the Bronze Age of Central Iberia. The settlement of La Motilla del Azuer. Written in bones: between technology and social realations. Proceding of the 7th Meeting of the ICAZ Worked Bone Research Group at Wroctaw, 7-11 September 2009. (J. Baron, B. Kufel-Diakowska, eds.), Uniwersytet Wrocławski. Wrocław: 273-284.

Anderung, C.; Boumman, A.; Persson, P.; Carretero, J.M.; Ortega, A.I.;Elburg, R.; Smith, C.; Arzuaga, J.L.; Ellegren, H.; Gotherstrom, A. (2005): Prehistoric contacts over the straits of Gibraltar indicated by genetic analysis of Iberian Bronze Age Cattle. PNAS, 102 (24): 8431-8435.

Andrés, M. T.; Barandiarán, J.M. (1964): La tumba Calcolítica de la Atayuela, treinta y cinco años después. Saldvie, 4: 85-124.

Apellániz, J. M. (1974): El grupo de los Husos durante la Prehistoria con cerámica en el País Vasco. Estudios de Arqueología Alavesa, 7: 7-409

Apellániz, J.M.; Nolte, E. (1966): Excavación, estudio y datación por $\mathrm{C}^{14}$ de la cueva sepulcral de Kobeaga" (Isparte, Vizcaya). Munibe, 3/4: 37-62.

ApellánIZ, J.M.; Marcos, J.L.; Domingo, S. (1983): Informe sobre el planteamiento, desarrollo, problemas y futuro del yacimiento arqueológico de "Cueva Mayor de Atapuerca" (Ibeas de Juarros, Burgos). Memoria técnica Inédita. Universidad de Deusto. Bilbao.

Apellániz, J.M.; Domingo, S. (1987): Estudios sobre Atapuerca (Burgos). II. Los materiales de superficie del santuario de la Galería del Sílex. Cuadernos de Arqueología de Deusto. Bilbao.

Aura Tortosa, J.E.; Pérez, C.I. (1998): ¿Micropuntas dobles o anzuelos? Una propuesta de estudio a partir de los materiales de la Cueva de Nerja (Málaga), (J.L. Sanchidrián, M.D. Dimón, eds.). Las culturas del Pleistoceno Superior en Andalucía. Patronato de la Cueva de Nerja, Málaga: 339-348.

Averbouh, A.; Bellier, C.; Billamboz, A.; Cattelain, P.; Cleyet-Merle, J.J.; Julien, M.; Mons, L.; Ramseyer, D.; Serone-Vivien, M.R.; WeltTe, A.C. (1995): Fiches Typologiques de l'industrie osseuse préhistorique. Cahier VII. Éléments barbéles et apparenté. Treignes. Edtions Cedarc.

BARANDiaRÁn, J.M. (1964): Excavaciones en Solacueva de Lacozmonte (Jócano, Alava). Campaña de 196162. Boletín Sancho el Sabio, 8 (12): 117-130.

BARANDiARÁN, J.M. (1967): El paleomesolítico del pirineo occidental. Bases para la sistematización tipológica del instrumental óseo paleolítico. Monografias Archaeologias, III. 
Barandiarán, I. (1978): La Atalayuela, fosas de inhumación colectiva del Eneolítico en el Ebro Medio. Príncipe de Viana, 152-153: 381-422.

BARCiela, V. (1992): Intercambio y trabajo de marfil en un poblado de la Edad del Bronce: El Cerro de El Cuchillo (Almansa, Albacete). Bolskan, 19: 75-84.

Barciela, V. (2006): Los elementos de adorno de El Cerro de El Cuchillo (Almansa, Albacete). Estudio tecnológico y funcional. Instituto de Estudios Albacetenses. Albacete.

BARgé, H. (1982): Les parures du Neolithique Ancien au début de l'Ade des Métaux en Languedoc. CNRS. Paris.

Barrios J.I.; Gallart M. D.; Mata, M.P. (2004): El yacimiento de Cueva Lóbrega (Torrecilla en Cameros, La Rioja): una visión acerca del Neolítico y la Edad del Bronce en el área occidental del Sistema Ibérico. Instituto de Estudios Riojanos. Historia. Arqueología, 15.

Botella, M., Alemán, I.; Jiménez, S.A. (1999): Los huesos humanos. Manipulación y alteraciones. Ed. Bellaterra, Barcelona.

Breuil, H.; Obermaier, H. (1913): Travaux executés en 1912. L'Antropologie, 24: 5-7.

Camps-Fabrer, H.; Ramseyer, D. (1990): Poinçons, Pointes, Poignards, Aiguilles. Fiches Typologiques de L'Industrie osseuse Prehistorique. Cahier III. Commision de Nomenclature sur L'Industrie de l'Os Prehistorique.

Carretero, J.M.; Ortega, A. I.; Juez, L.; Pérez González, A.; Arsuaga, J.L.; Pérez Martínez, R.; Ortega, M.C. (2008): A Late Pleistocene-Early Holocene archaeological sequence of Portalón de Cueva Mayor (Sierra de Atapuerca, Burgos, Spain). Munibe, 59: 67-80.

Carmona, E.; Arnaiz, M. Á.; Montero, J. (2010): Consumo de metal durante la Prehistoria Reciente en el centro de la Península Ibérica. Una aproximación a través del análisis de los contextos funerarios en fosa. Trabajos de Prehistoria, 67: 373-387.

CEniceros, J.; BARrios, I. (1988): Reinterpretación de las estratigrafías y ajuares arqueológicos de Cueva Lóbrega (Torrecilla de Cameros, La Rioja). Brocar, 14: 53-102.

Cheyner, A. (1967): Comment vivait I'homme des Cavernes a l'Age du Renne (R. Armoux, ed.), Paris.

Clark, G.A. (1979): The North Burgos Archaelogical Survey. Bronze and Iron Age archaeology on the Meseta del Norte (Province of Burgos, North-Central Spain). Anthropological Research Papers, 19. Arizona State University. Dept. of Antropology, Arizona.

Delibes de Castro, G.; Fernández, J. (1983): Calcolítico y Bronce en tierras de León. Lancia, 1: 19-52.

Delibes, G.; Rojo, M.; SAnz, C. (1986): Dólmenes de Sedano II. El sepulcro de corredor de Las Arnillas (Moradillo de Sedano, Burgos). Noticiario Arqueológico Hispano, 27: 7-41.

Delibes, G.; Romero, F.; Abarquero, F.J. (2000): Cerámicas excisas de discutible filiación Cogotas I en el Bronce Tardío de la Península Ibérica: una taza de estilo Duffaits procedente de la Cueva del Asno (Los Rábanos, Soria). Soria Arqueológica, 2: 97-130.

Delibes de Castro, G.; Val Recio, J. (2007-2008): La explotación de la sal el término de la Edad del Cobre en la Meseta Central española: ¿Fuente de riqueza e instrumento de poder de los jefes de Ciempozuelos? Veleia, 24-25: 791-811.

Estremera, M.S. (2003): Primeros agricultores y ganaderos en la Meseta Norte: el Neolítico de la Cueva de La Vaquera (Torreiglesias, Segovia). Memorias. Arqueología en Castilla y León, 11.

Fernandez Eraso, J. (2003): Las Yurdinas II: un depósito funerario entre finales del IV y comienzos del III milenio BC. Memorias de yacimientos alaveses, 8 .

Fernández-Miranda, M.; Fernández-Posse, M.D.; Gilman, A.; Martín, C. (1994): La Edad del Bronce en la Mancha Oriental. Actas del Simposio la Edad del Bronce en Castilla y la Mancha, Toledo: 243-287.

García, J.; Sesma, J. (2007): Enterramientos en el poblado neolítico de los Cascajos (Los Arcos). La tierra te sea leve .Arqueología de la muerte en Navarra. Exposición del museo de Navarra.

Garcia Sanjuan, L.L. (2013): Ivory craftsmanship, trade and social significance in the southern Iberian Copper Age: the evidence from the PP4 Montelirio sector of Valencina de la Concepción (Sevilla, Spain). European Journal of Archaeology doi.

KAISER, J.M. (2004): Sobre el origen extrapeninsular de algunos tipos de puntas de flecha de la Edad del Bronce. Archivo de Prehistoria Levantina, XXV: 127-160. 
Liesau von LetTow-Vorbeck, C. (2011-12): Materias primas y objetos de prestigio en ajuares funerarios como testimonios de redes de intercambio en el horizonte campaniforme. Cuadernos de Prehistoria y Arqueología de la Universidad Autónoma de Madrid, 37-38: 209-222.

López Padilla, J.A. (2006): Distribución territorial y consumo de botones de perforación en V en el ámbito agárico. Trabajos de Prehistoria, 62 (2): 93-116.

López Padilla, J.A. (2009): El irresistible poder de la ostentación: la artesanía del marfil en Lorca en la época del Argar. Alberca, 7.

López Padilla, J.A. (2011): Asta, hueso y marfil. Artefactos óseos de la Edad del Bronce en el Levante y Sureste de la Península Ibérica (c.2500-c.1300 cal BC), MARQ. Museo Arqueológico de Alicante, Alicante.

LLanos, A. (1991): Excavaciones en la cavidad de Solacueva de Lakozmonte (Jocano, Álava). Campañas de 1980-1981. Isturitz, 4: 121-156.

MaICAS, R. (2003-2004): Algunas consideraciones sobre la industria ósea del Neolítico y Calcolítico en la Cuenca de Vera, Almería. Espacio, Tiempo y Forma, Serie I, Prehistoria y Arqueología, 16-17: 161-188.

MaIcas, R. (2007): Industria ósea y funcionalidad: Neolítico y Calcolítico en la cuenca de Vera. Bibliotheca Praehistorica Hispana. CSIC, Madrid.

Maluquer de Motes, J. (1963): Notas sobre la cultura megalítica navarra. Príncipe de Viana, 92-93: 3-147.

Mínguez, M.T. (2001): Los pastores de la población de cavernas de Atapuerca y de la Meseta durante el Bronce Final. Tesis Inédita. Universidad de Deusto.

Mínguez, M.T. (2005): Estudios sobre Atapuerca (Burgos): III. Los materiales del Bronce Final de El Portalón de Cueva Mayor. Excma. Diputación de Burgos y Universidad de Deusto. Cuadernos de Arqueología, 20.

Pascual Benito, J.L. (1998): Utillaje óseo, adornos e ídolos neolíticos valencianos. Diputación Provincial de Valencia. Trabajos Varios del Servicio de Investigaciones Prehistóricas, 95.

Pérez, C.L.; López de Calle, C. (1986): Aportaciones al estudio de las culturas Eneolíticas en el Valle del Ebro. I: Elementos de adorno. Historia/3. Gobierno de la Rioja. Instituto de Estudios Riojanos. Logroño.

Pérez Romero, A. (2009): Prehistoria e Historia en El Portalón de Cueva Mayor (Sierra de Atapuerca, Burgos). Master Tesis. Inédito.

RodAnÉs, J.M. (1987): La industria ósea prehistórica en el Valle del Ebro. Diputación General de Aragón.

SAmpayo, P., Zuaznávar, M. (1968): Descripción con planos de la cueva llamada de Atapuerca. Kaite, II: 5-19.

Schunmacher, T.B. (2013): The use of sperm whale ivory in Chalcolithic Portugal. Trabajos de Prehistoria, 70 (1): 185-203.

Schuhmacher, T.; Banerjee, A. (2012): Procedencia e intercambio del marfil en el Calcolítico de la Península Ibérica. Xarxes al Neolític. Rubricatum, 5: 289-298.

Uscatescu, A. (1992): Los botones de perforación en "V" en la Península Ibérica y las Baleares durante la Edad de los metales. Temas de Arqueología, 2.

Vargas, J.M., Nocete, F.; Schuhmacher, T. (2012): Contextos de producción de marfil en Valenciana de la Concepción (Sevilla). En Banerjee; A.; López Padilla, J.A. y Schuhmacher, T., Marfil y Elefantes en la Península Ibérica y el Mediterráneo. Iberia Archaeologica, 16 (1): 69-81.

Vergés, J.M.; Allué, E.; Angelucci, D.E.; Cebrià, A.; Díez, C.; Fontanals, M.; Mányanos, A.; Montero, S.; Moral, S.; Vaquero M.; Zaragoza, J. (2002): La Sierra de Atapuerca durante el Holoceno: datos preliminares sobre las ocupaciones de la Edad del Bronce en la Cueva de El Mirador (Ibeas de Juarros, Burgos)". Trabajos de Prehistoria, 59 (1):107-126.

Voruz, J.L. (1987): Typologie analytique d'industries osseusses néolithiques. L'industrie en os et bois de cervidé durant le Néolithique et l'Age des Metaux II. Paris. C.N.R.S.: 77-105.

Zapata, L. (1995): La excavación del depósito sepulcral Calcolítico de la cueva Pico Ramos (Muzquiz, Vizcaya). La industria ósea y los elementos de adorno. Munibe, 47: 35-90.

Zapata, L.; IbAÑEZ J.J.; GonZÁlez, J. (1997): El yacimiento de la cueva de Kobaederra (Oma, Kortezubi, Vizcaya). Resultados preliminares de las campañas de excavación 1995-971. Munibe, 4: 51-63. 